\title{
Pedagogies of Academic Writing in Teacher Education: from Epistemology to Practice and back again
}

\section{Beighton, Christian; Blackman, Alison}

Post-Compulsory Education and Training, Canterbury Christ Church University, England.

\begin{abstract}
This paper discusses barriers to the development of academic writing, in the area of teacher education in UK higher education. We first situate these issues in a higher education context increasingly defined by new technologies and diverse cohorts of higher education students. Drawing on empirical data obtained from interviews with both students and teachers $(N=21)$, we then critically examine a range of perspectives on the definition, role and function of academic literacy in this contemporary context. Findings include useful insights into the development of writing skills and teacher identity, but they also reveal fundamental differences in the epistemological presuppositions of those teaching academic writing. These accounts are reflected in significant differences in pedagogy, and raise important questions for practice which, although potentially irresolvable, may help to explain some of the difficulties which emerge when trying to teach academic writing. Such fundamental issues, we argue, need to be at least recognized if teachers hope to develop the writing capacity of trainee teachers in an academic context.
\end{abstract}

Keywords: Academic Writing; Teacher Education; Epistemology; Pedagogy. 


\section{Introduction}

A recent green paper from the UK government, Fulfilling our Potential: Teaching Excellence, Social Mobility and Student Choice, aims to reshape the higher education landscape with a greater emphasis on students' needs and quality of provision (BIS, 2015). These proposals have put the spotlight on the learner experience and teaching quality in higher education, one of the impacts of globalization.

This paper, accordingly, focuses on academic writing, which plays a central, if contested, role in the treatment of knowledge, indeed wider definitions of higher education (HE) study, as well as in provision and assessment of pedagogical quality (see, for example, Lea and Street, 1998; Rolfe, 2013). However, HE's continued dependence on certain writing conventions as an expression of academic ability and employment potential is open to question, as are the pedagogies related to the acquisition of the relevant skills - if indeed the practice of writing can be described in this way. Critics see the latter as reductive and a reflection of the inequalities heralded by globalization and neo-liberalization of higher education, (e.g. Badenhorst et al, 2015, Shay and Peseta, 2016). If higher education's ratio essendi includes contributing to the development of democracy, access and social justice (Badley, 2016), how far do academic writing pedagogies help or hinder this goal?

Some recent work on the topic has reiterated the need for a practice framework to develop academic writing (Lillis, 2003; Wingate, 2014; Cannady and Gallo, 2016). The goal is to develop pedagogies that prepare students for both academic and professional success while avoiding reducing the practice to the parroting of a set of skills and reproducing a status quo which perpetuates an anachronistically exclusive view of what higher education should be. We want to show in this paper, however, that such pedagogies must reflect the views of the teachers who implement them if they are to be successful, since teachers play an agential role in establishing, maintaining and changing things at the level of practice. The data presented below suggests that teachers' presuppositions define both what is taught as academic writing and how. To clarify these aspects of teachers' critical, epistemological and pedagogical perspectives, we look closely at how practitioners in the area of teacher education teach academic writing. Drawing on an empirical study, our findings indicate specific responses to the question of what academic writing means in this context and how it should be taught from the perspective of those who teach and indeed learn it. Our analysis identifies underlying themes and distinct rationales behind these choices, emphasizing the ultimate impact of these presuppositions on the student experience. 


\section{Method}

A pilot study was first undertaken with two cohorts of students writing at masters level in order to establish hypotheses which were then discussed in a conference presentation. These informed a further study with respondents $(\mathrm{N}=21)$ who were professionally involved in teacher education. Semi-structured, face-to-face interviews of teachers and student were used to investigate our hypotheses: respondents were asked to define academic writing, explain why it was important, highlight barriers to the successful development of academic writing skills, and critically discuss writing pedagogies. Recordings were made and transcriptions added to notes made during the interviews for analysis.

It's notable that this cohort reflected a typical feature of teacher education in that many respondents were at the same time students, teachers and teacher educators, being involved in doctoral study alongside their teaching role. In the UK, it is common for practitioners to work in their teaching role while conducting further study in higher education at the same time. This includes HE lecturers, who may carry out their professional role, for example teaching academic writing to trainee teachers, while carrying out research for a doctorate. Each interview threw up individual issues pursued in other publications, but in this paper we'd like to focus on teacher education as arguably the key area in the debate mentioned above about how to develop pedagogies for academic writing in the current context. For this reason, we present three colleagues whose responses to the questions were both specific enough to recognize the variety in the ways academic writing is taught and learnt, and generic enough to suggest wider lessons for a pedagogy of writing in and for the university.

\section{Odette (names changed for anonymity)}

Odette is an experienced teacher educator who grew up outside the UK. For her, academic writing is "just another genre of writing". It is defined by certain rules and the existence of an identifiable community which respects them. It therefore reflects the demands of a literate society which prizes the written form and, therefore, differs from other genres only insofar as it is prescribed by an academic community and the rules that bind it. Odette felt no particular need to criticize or defend these prescriptions. This collective perspective, according to which writing conventions exporess a community of values, matters because it implies a particular purpose, content and even style of writing, she said: 
It's also an attempt to create a genre that reflects a way of thinking, so the content is about thought, that is not just a personal narrative but has some kind of basis in other people's research, other people's thinking, sometimes in the thinking of recognized, knowledgeable people / gurus in the field.

Odette's views, she said, are already at odds with those in teacher education who prize "personal narratives" as a research resource. For her, academic writing is all about a shift from a subjective perspective to a more socially constructed one. She described this as forming a "net that holds things together" which is always produced by and with other people. At the same time, Odette recognized the irony in the fact that practices which bind a genre and its community also, as she put it, "keep people in their jobs". More importantly for her, though, the social nature of academic writing can be a distraction in that it tends to encourage a focus on consensual, stylistic aspects of text to the detriment of other, more difficult and perhaps more important issues of substance:

[This] keeps people worrying about how many references and things, how many commas etc ( ...) I wonder sometimes if it's because other issues are harder to grapple with. Harder to give somebody feedback on, and also harder to teach or, sort of, coach people at getting better at.

Speaking of her pedagogical choices, she felt that while examples are important, they must be "not too far beyond the level of where the students are now". Working on texts in groups can be helpful, particularly sharing examples of peers' writing. Focused "awareness-raising" work on specific vocabulary and sentence structure is useful, especially when English is a students' second or third language. But while there should be a focus on style as well as content, this should not eclipse the latter:

But I try not to so too much on "you're missing a comma"...I give much more feedback on "you haven't got your paragraph right" than I do about things like commas, because I think they are the things that are ignored, that [teachers] are afraid to tackle.

\section{Beth}

Beth is also originally from outside the UK. Currently working in teacher education, her professional role includes a focus on academic writing at Masters level (level 7 in the UK HE qualification framework). She felt that "the best academic writing is something you want to read", but her definition of academic writing differed from Odette's in its emphasis on logic and structure. Thus as a "logical way of putting forward ideas", it should be clear, well-structured and readable and follow certain established HE conventions. Its ideas should relate to the question or topic in hand, and should 
"incorporate" the views of other theorists, suggesting that these were secondary in some way to what Odette called the individual's own story. In addition, for Beth, students should also provide a critical account, which meant an essentially dialectic procedure of making sure the text was "relevant to the arguments for and against". This was something that students should "hopefully" do, suggesting that, again, this aspect of writing was a goal rather than a criterion.

Like Odette, Beth felt that writing involved producing work defined more by its "higher quality" than "non-academic institutions". She was not unusual in highlighting the circularity of this argument, and pedagogically, Beth was clear that support is needed:

It's bit like learning to cook. If you've never read a recipe before, you're a bit confused by what you're supposed to do, and if you're asking someone to make a four-course meal and they don't know how to boil an egg, then of course it's going to seem insurmountable.

Beth's sensitivity to the challenges that one's background might impose on the task meant that she felt that one-to-one support is "much better than having group sessions", since individuals come with very specific issues which can't necessarily be addressed in groups. The first thing is always to look at what they have written, and then show other examples which can make the penny drop. She insisted on the visual importance of being "able to picture it" in order to understand the structures, approaches and language required.

Part of the role of pedagogy, then, is to tackle the barriers to academic writing. The first of these, Beth felt, is the lack of pedagogy, in that academic writing is simply not taught at all in many cases:

It doesn't tend to be taught, that's the problem and so it's held up as a sort of monolith to students as something they are supposed to achieve and they have no idea what it means or how to do it, so it's actually quite frightening.

She first highlighted language as a big barrier, and the assumption in some students that what is required is "some kind of Dickensian English". This is made more difficult, however, by what she calls the "pomposity of an awful lot of academics", for whom writing is an "ego trip". Beth was very critical of those whose stance on writing is dogmatic - proscribing first person subject pronouns was the example she gave - and recognized "brilliant academics" by their coherence and ability to articulate what academic writing is about without seeming pompous. 
Fear of failure was also a barrier, apart from a lack of ability, which might come from having a background in other "languages" (maths, engineering for example). But an equally important problem for Beth is the potential threat to identity. Students from other cultures struggle with the conventions and norms, particularly those governing the kinds of relationships that are expected with teachers:

If they have grown up in a culture where the academic is put on a pedestal, an unattainable God-like figure, then again they don't actually think they'll ever be able to be like that. (...) I want to do this course, but I don't want to become like you. I don't want to become the sort of person that my family, my friends won't like.

Interestingly, she felt that support for learners with these barriers has to be more attractive to the learner if it is to be taken up. Unfortunately, she said, support is not always promoted in a helpful way by academics who, rather than help the learner, wash their hands of them:

Sometimes we say "go along there for study skills" (...) We tend to say, that's not my job, I'm an academic, I don't do study skills, there are people over there who do that.

Even when support has been provided though, degree-level qualifications are awarded even when writing skills are not up to the expected standard. Her conclusion was that "I think there's a lot of sloppiness out there".

\section{Bella}

Despite similarities in some points, Bella's definition of academic writing differed fundamentally from both Odette's and Beth's. Rather than focus on the demands of a community or genre (Odette) or on the need to express one's own ideas (Beth), writing for Bella is more about working on "the body of knowledge that is out there". Like her colleagues, Bella was well aware of the role of convention and the fact that writing can seem a rather self-justifying activity. For her though, academic writing is the ability to summarize, organize and contextualize the work of others. Bella's epistemological standpoint informs what she means here, since for her existing knowledge was to be "gathered" by the writer into "some kind of concise form". This gathering involves transferring and translating, and tellingly focuses on reading as a source of information to be summarized. 
Bella echoed the view that a challenge exists in teacher education for those qualified in subjects where academic literacy is not usually expected, making academic writing something of an alien practice. Teachers then often wrongly assume that everyone understands how to organize their thinking and thus the first step is to provide a "very easy recipe" for clarity:

Number one I give them a formula, and I always say I'm not after Oscar Wilde, I'm not after beautiful writing, I'm after clarity and I always say you've got to explain the what, the how, the why, the why not, the improvements and the limitations.

She also felt that explicit work on a range of others' writing was helpful, focusing on students' work (essays) to help identify strengths and weaknesses in the organization, in how the knowledge is presented, or in how quotes are being used. She asks questions about strategy ("was it an effective way of approaching it or not"), and "technical stuff" for example by providing deconstructed essays which the students reorganize in order to look for logic, successful threads and so on. Ultimately, though, for Bella, the approach should not be too prescriptive, because of the different needs of the different writers. This means "always letting them have a go", providing plenty of practice and feedback which comments on content as well as on style, and the chance to develop both an individual "voice" and a set of practices that work. Both are emergent phenomena for Bella who, like Beth, felt that confusion was an important response to the problems of writing.

\section{Discussion}

Odette, Beth and Bella all show the confidence in describing their practice that one would expect from experienced teachers in this context. This suggests that little has changed in this regard since Lea and Street's findings in 1998: teachers of academic writing tend to have clear but often contradictory ideas about what they are teaching.

This being said, fundamental differences in epistemological outlook marked these three accounts, suggestive of constructivist, social constructivist and realist presuppositions. Beth's suspicion of the social context in which we learn to write leads her to take a constructivist stance according to which knowledge is built at an individual level. Only subsequently is it refined in the light of rational debate and, up to a point, in the face of institutional threat and the "sloppiness" she suspects exists in some situations. Her pedagogical choices follow this line, focusing strongly on individual support and expression. Odette's social constructivist position contrasts with this, since for her knowledge and its acquisition are defined by essentially communal parameters. Her 
preferred pedagogical activities reflect this outlook, for example in their focus on group work, shared texts and an eye for content expressed in an accessible way. All accept that the construction of knowledge relies more on communicability than on details of form. Bella's view, finally, differs radically from both the others in taking a more realist perspective according to which knowledge is "out there" to be processed by the writer. Pedagogically, her activities focused on the kinds of practice which would help the writer deal with the predictable confusion faced by the inevitable challenge of what is "out there".

These differences are interesting in themselves, and represent a healthy diversity in teachers' outlook. But they raise several questions for pedagogies of academic writing. First, are teachers aware of the epistemological presuppositions which underpin their pedagogical preferences? If so, how critically do they treat these presuppositions, and how aware are they of other perspectives? Second, are teachers conscious that their pedagogical choices may be driven by these epistemological presuppositions, and that this may limit the way they respond to learners' own more or less tacit epistemological expectations? Third, are teachers aware that close colleagues might have radically different views on these topics, and that these views may well differ radically from those the student has heard before? Do they know that advice, teaching and support may be completely different as a result?

\section{Conclusion}

Despite the technicist discourse of academic skills and criterion-referenced assessment, the teachers in this study show how individual epistemological assumptions, deficit discourses and institutional requirements play a key role in defining the details of academic writing pedagogies. Despite their similarities, as soon as the details are examined, we see important differences in how three colleagues actually go about teaching and assessing academic writing. These differences are a form of "discoursal dissonance" whose reduction, it has been argued, can empower students (Saunders and Clarke, 1997). Such dissonance within an individual discipline and between individual professionals may well have an impact on the academic's own development as they engage in writing for publication, but perhaps the most important question regards the possible impact of these differences on students and their work. Additionally, if teachers themselves find the decidedly non-textual activities of experience, experiment and observation most beneficial as applied learning activities (van den Bos and Brouwer, 2014), why do we continue to rely on academic writing as a vehicle for knowledge? What 
is the future for academic writing whose pedagogies are based on the transmission of formal features with little or no regard for content, ideas or originality?

These questions may well reflect what Jean-Francois Lyotard (1983) calls a différend: a difference of opinion based on valid but fundamentally incompatible and conflicting premises. As such, academic writing is an ethical problem at the heart of today's academy. Perhaps, as Bella suggests, our task is to familiarize students with these potentially confusing differences. But unless teachers of academic literacy can address these questions, students may continue to see academic writing as pompous and confusing, undermining retention and success. In a context of rising student expectations and the spoonfeeding, pass-at-all costs culture (cf. Itua et al, 2014; Cahill et al, 2015; Masika and Jones, 2016) teachers risk adhering to plans which, while successfully prescribing the outcomes of central educational processes, remain a failure (cf. Hagström and Lindberg, 2013).

\section{Acknowledgements}

We are grateful to all who participated in this study, particularly those from Bristol University who did not take part, but whose support was invaluable.

\section{References}

Badenhorst, C.; Moloney,C.; Rosales,J.; Dyer,J; and Ru,L. (2015). Beyond deficit: graduate student research-writing pedagogies. Teaching in Higher Education, 20(1), 111.

Badley, G. (2016). The pragmatic university: a feasible utopia?. Studies in Higher Education, 41(4), 631-641.

BIS (2015). Fulfilling our Potential: Teaching Excellence, Social Mobility and Student Choice. Retrieved from http://www.parliament.uk/bis.

Cahill, J.; Bowyer, J.; Rendell, C.; Hammond, A. and Korek, S. (2015). An exploration of how programme leaders in higher education can be prepared and supported to discharge their roles and responsibilities effectively. Educational Research, 57(3), 272286.

Cannady, R.E and Gallo, K.Z. (2016). Write Now! Using reflective writing beyond the humanities and social sciences. Journal of Further and Higher Education, 40(2), 188206.

Hagström, E. and Lindberg, O. (2013). Three theses on teaching and learning in higher education. Teaching in Higher Education, 18(2), 119-128. DOI: $10.1080 / 13562517.2012 .694097$ 
Itua,I.; Coffey, M.; Merryweather, D.; Norton, L. and Foxcroft, A. (2014). Exploring barriers and solutions to academic writing: Perspectives from students, higher education and further education tutors. Journal of Further and Higher Education, 38(3), 305-326.

Lea, M.R. and Street, B.V. (1998). Student writing in higher education: an academic literacies approach. Studies in Higher Education, 23(2), 157-172.

Lillis,T. (2003). Student Writing as 'Academic Literacies': Drawing on Bakhtin to Move from Critique to Design. Language and Education, 17(3), 192-207. DOI: 10.1080/09500780308666848

Lyotard, J-F. (1983). Le Différend. Paris: Minuit.

Masika, R. and Jones, J. (2016). Building student belonging and engagement: insights into higher education students' experiences of participating and learning together. Teaching in Higher Education, 21(2), 138-150.

Rolfe, G. (2013). The University in dissent: Scholarship in the Corporate University. London: Routledge.

Saunders, C. and Clarke, J. (1997). Negotiating Academic Genres in a Multi- disciplinary Context. Journal of Further and Higher Education, 21(3), 297-304.

Shay, S. and Peseta, T. (2016). A socially just curriculum reform agenda. Teaching in Higher Education, 21(4), 361-366. DOI: 10.1080/13562517.2016.1159057

van den Bos, P. and Brouwer, J. (2014). Learning to teach in higher education: how to link theory and practice. Teaching in Higher Education, 19(7), 772-786.

Wingate, U. (2015). Academic Literacy and Student Diversity. Bristol: Multilingual Matters. 